\title{
Nature-based Solutions (NbS) - what are they and what are the barriers and enablers to their use?
}

Roz Price

Institute of Development Studies

5 May 2021

\section{Question}

- 'Nature based Solutions (NbS) 101' review covering: what are NbS? The pros and cons of NbS? Design and implementation issues (equity, governance, indigenous knowledge etc')? Finance and the enabling environment?

\section{Contents}

1. Summary

2. What are Nature based solutions (NbS)

3. Design and implementation issues and barriers

4. Financing and the enabling environment

5. Knowledge gaps

6. References

The K4D helpdesk service provides brief summaries of current research, evidence, and lessons learned. Helpdesk reports are not rigorous or systematic reviews; they are intended to provide an introduction to the most important evidence related to a research question. They draw on a rapid deskbased review of published literature and consultation with subject specialists. 


\section{Summary}

Nature-based Solutions (NbS) are defined by the International Union for Conservation of Nature (IUCN) as (Cohen-Shacham et al., 2016, p. xii):

\section{Actions to protect, sustainably manage and restore natural or modified ecosystems, which address societal challenges (e.g. climate change, food and water security or natural disasters) effectively and adaptively, while simultaneously providing human well-being and biodiversity benefits.}

$\mathrm{NbS}$ interventions can take many forms and have been applied in a wide variety of sectors and to address a plethora of societal issues (Cohen-Shacham et al., 2016). NbS builds on years of experience of ecosystem approach, and have gained international popularity in recent years as an integrated approach that could address both climate change and biodiversity loss, whilst also supporting a range of the sustainable development goals (Seddon et al., 2020). At their simplest, $\mathrm{NbS}$ harness nature functions to adapt to and mitigate climate change while enabling local benefits, for example water functions, biodiversity protection and human wellbeing (Raymond et al., 2017). Seddon et al. (2021, p. 1524) go a step further and say that successful and sustainable NbS must deliver benefits for biodiversity and people. As such, trade-offs and synergies play key roles in the design of $\mathrm{NbS}$.

The breadth of $\mathrm{NbS}$ and the evidence base means that this rapid review only provides a snapshot of the information available, and therefore does not consider all types of $\mathrm{NbS}$, nor all sectors that they have been used in. For more in depth readings of $\mathrm{NbS}$ and the barriers and enablers to their use please see Kapos et al., 2019; OECD, 2020; and Seddon et al., 2020 and 2021.

Considering this limited scope, this report highlights the following:

- Covid-19 has highlighted the importance of NbS: With the background of the ongoing Covid-19 pandemic, solutions to societal issues that work with nature are more relevant than ever before (GCA, 2021).

- Pros of NbS include: they can be low cost compared to infrastructure alternatives; can be flexible and can address multiple climate challenges; can be designed to have other co-benefits such as better water quality, improved health, cultural benefits, biodiversity conservation etc (Kapos, 2019). Furthermore, they are a carbon capture solution that is available now, unlike technologies such as Carbon Capture and Storage.

- Cons of NbS include: they can be slow to realise adaptation or co-benefits; benefit-cost ratios can be variable over time given potential delays to accrual of benefits; tend to be very context specific making effectiveness difficult to measure; NbS themselves may be climate-sensitive (Kapos, 2019); many of the benefits are non-monetary and hard to measure.

- $\quad \mathrm{NbS}$ are not a 'silver bullet' and do not operate in a governance vacuum: It is important not to over-simplify NbS or be unrealistic about their impacts. NbS are not a substitute for rapid decarbonisation. They should be viewed as both an opportunity but also a challenge - as a strong understanding of ecosystem processes is needed, a variety of stakeholders must be engaged, and a comprehensive set of societal issues needs to be included and integrated (Nesshöver et al., 2017). Justice dimensions (such as land rights and power structures) need to be continually considered in $\mathrm{NbS}$ (van der 
Jagt et al., 2021). A holistic approach to NbS design, implementation and assessment is key (Raymond et al., 2017).

- Key barriers to scaling-up NbS: a lack of awareness/understanding of NbS approaches and nature's critical role in adaptation (entrenched attitudes and norms); lack of accessible funds and flawed approaches to economic appraisal lead to underinvestment in NbS; many benefits from NbS are difficult to monetise; limited availability of knowledge and evidence to help make the business case for their use (especially against businessas-usual alternatives); inflexible and highly sectoralised policy, regulatory environments, existing direct and indirect subsidies and governance challenges, continue to favour grey, engineered solutions; technical challenges and gaps in capacity that impede wider implementation (Kapos et al., 2019; Seddon et al., 2020).

- Measuring the effectiveness of NbS is difficult: Despite the growing attention and evidence base for $\mathrm{NbS}$, measuring effectiveness remains difficult, and intentions (or commitments to $\mathrm{NbS}$ ) have yet to fully translate into measurable, evidence-based targets for NbS and action on the ground (Chausson et al., 2020).

- Trade-offs analysis is key: While technological responses tend to focus on a single benefit, NbS' approach to multiple benefits has higher potential for conflict between objectives. For example, an overly simplified large scale monoculture afforestation to mitigate $\mathrm{CO} 2$ can negatively affect biodiversity and water resources. The identification and measurement of trade-offs by multiple stakeholders, and potential compensation interventions is key to reduce potential conflict and enhance long-term effectiveness (Dasgupta, 2021; Giordano et al, 2020).

\section{Other key sources}

This rapid evidence review builds on previous K4D helpdesks, which may provide further information and insights on issues around innovative financing and $\mathrm{NbS}$ (see Cooper \& Matthews, 2020); NbS and water security (see Cooper, 2020b); and more broadly biodiversity conservation/restoration and poverty reduction (see Cooper, 2020a). There has been an upsurge in interest and research around NbS in recent years, and accordingly an increase in the evidence base. In particular, useful resources for further information and key projects looking at exploring the evidence base on effectiveness include: Kapos et al., 2019; OCED, 2020; Raymond et al., 2017; Reid et al., 2019; Seddon et al, 2020, 2021.

\section{Evidence base}

This rapid literature review largely draws on grey and academic literature, much of which are systematic reviews or based on case study analysis. The evidence base on $\mathrm{NbS}$ is nascent and growing, with a rapid increase in the number of peer-reviewed academic papers in the last few years. Due to the time constraints of this rapid review, it was not possible to review all the literature related to $\mathrm{NbS}$, and so systematic reviews and recent literature (within the last 5 years) was prioritised.

\section{The literature consulted suggest a number of knowledge gaps in the evidence base for $\mathrm{NbS}$ effectiveness including lack of: robust and impartial assessments of current $\mathrm{NbS}$ experiences; site specific knowledge of field deployment of NbS; timescales over which benefits are seen and experienced; cost-effectiveness of interventions compared to or in conjunction with alternative solutions; and integrated assessments considering broader social and ecological outcomes (Chausson et al., 2020; Cooper \& Matthews, 2020; WWAP/UN-Water, 2018).}


The evidence base also appears to be biased towards implementation in developed countries in the Global North (especially North America and Europe) (Chausson et al., 2020); despite this, attention, funding, and evidence is growing elsewhere including South America, throughout Asia-Pacific, and in Africa. The evidence base is also dominated by certain NbS and ecosystems, such as establishment or management of created habitats and forests (Chausson et al., 2020).

\section{What are Nature based solutions (NbS)}

\section{Definition}

The term NbS has been defined and used in a number of different ways, although the IUCN definition is widely embraced by most organisations and the conservation community. For example, the European Commission (EC) provides an alternative perspective on NbS' remit and purpose than the IUCN (Nesshöver et al., 2017). The EC understands NbS as actions that "aim to help societies address a variety of environmental, social and economic challenges in sustainable ways. They are actions which are inspired by, supported by or copied from nature" (European Commission, 2015, p. 5). Shacham-Cohen (2019, p. 22) explains that the EC's framing has a "larger focus on urban ecosystems, due to the high percentage of the population of Europe that lives in cities and the need to address challenges such as human health, climate change and degradation of natural capital," whilst the IUCN's definition "was developed from a global perspective, considering all types of ecosystems, but focusing primarily on protection and management of natural ecosystems." The IUCN provides 8 principles in conjunction with its NbS definition, to help IUCN and other organisations build a common language and understanding of NbS (Cohen-Shacham et al., 2016; 2019). ${ }^{1}$

\section{$\mathrm{NbS}$ can be considered an umbrella concept that covers a large range of ecosystem- related terms and approaches, all of which address societal challenges. Other terms its associated with include ecosystem-based adaptation (EbA), agroforestry, agro-ecology, green/blue infrastructure, natural climate solutions (NCS), reduced emissions from deforestation and degradation+ (REDD+) etc. Concepts include blue carbon, natural capital, ecosystem services etc. (see Seddon et al, 2021, p. 1520 for more information and further definitions; see also Table 2 in Nesshöver et al., 2017, pp. 1218-1219). IUCN has placed these approaches into five main categories of NbS approaches (Cohen-Shacham et al., 2019, p. 22): Restorative (e.g. ecological engineering, ecological restoration); Issue-specific (e.g. ecosystem-based adaptation, ecosystem-based disaster risk reduction); Infrastructure-related (e.g. green infrastructure); Management (e.g. Integrated coastal zone management); and Protection (e.g. Area-based conservation).}

\footnotetext{
1 The 8 principles (Cohen-Shacham et al. 2019, pp. 23-25): (1) NbS embrace nature conservation norms (and principles); (2) NbS can be implemented alone or in an integrated manner with other solutions to societal challenges (e.g. technological and engineering solutions); (3) NbS are determined by site-specific natural and cultural contexts that include traditional, local and scientific knowledge; (4) NbS produce societal benefits in a fair and equitable way, in a manner that promotes transparency and broad participation; (5) NbS maintain biological and cultural diversity and the ability of ecosystems to evolve over time; (6) NbS are applied at the scale at a landscape; (7) NbS recognise and address the trade-offs between the production of a few immediate economic benefits for development, and future options for the production of the full range of ecosystems services; (8) NbS are an integral part of the overall design of policies, and measures or actions, to address a specific challenge.
} 
$\mathrm{NbS}$ emerged at the science-policy-practice interface, and as a term is relatively recent, especially its use by practitioners and policy makers. However, many of the terms and practices it encompasses are not new and have been around for many decades (and longer). Uniting these concepts within a single framework (i.e. $\mathrm{NbS}$ ) helps practitioners to design and implement interventions in nature in a flexible and integrated manner that considers the full range of potential outcomes and provide multiple benefits and minimise trade-offs (Seddon et al., 2021, 1521). As long as NbS approaches are designed and implemented properly (see sections 3,4 and 5).

NbS have gained a lot of policy attention in recent years and has moved rapidly up political agendas. This includes being highlighted in recent high-level global assessment reports by e.g. the Intergovernmental Panel on Climate Change (IPCC) and the Intergovernmental Science-Policy Platform on Biodiversity and Ecosystem Services (IPBES), and being recognised in international agreements and conventions, including the United Nations Framework Convention on Climate Change (UNFCCC) and its Climate Action Pathways ${ }^{2}$ (Chausson et al., 2020; Seddon et al., 2021; Kapos et al., 2019). For example, 70 out of 167 initial Nationally Determined Contributions (NDCs) submitted under the Paris Agreement include actions broadly aligned with $\mathrm{EbA}$, and a further 33 countries refer to conservation activities - and these commitments are more prevalent among developing countries compared to high-income countries (Kapos et al., 2019, p. 18). NbS are also the focus of a growing number of programmes by governmental and non-governmental organisations, and the private sector (Seddon et al., 2021, p. 1521). However, in most cases ambition for NbS does not match practice (OECD, 2020).

Due to its broad framings NbS can at times appear vague or unclear (Nesshöver et al., 2017) - and there has been some confusion over the term and what 'counts' as an NbS "and the extent to which NbS represent a departure from existing concepts and practices" (Seddon et al., 2021, p. 1521). The addition of the term NbS for adaptation (NbSA), has created further confusion, as a common definition for what this entails does not yet exist (Swann et al., 2021).

Much work has been done to improve the conceptualisation of NbS including the development of global standards by both the IUCN (2020) and OECD (2020 - aimed at NbS to address water-related climate risks). In 2020, IUCN released its Global Standard on Nature-based Solutions - setting out 8 criteria for good NbS ${ }^{3}$ (IUCN, 2020). The Global Standard is facilitative, aiming to guide the user in design and implementation but also to continuously impr ove the intervention's resilience and help prepare for uncertainty. ${ }^{4}$ However, a number of concerns with $\mathrm{NbS}$ uses remain (see Trade-offs and concerns sub-section).

\footnotetext{
2 See https://unfccc.int/news/un-climate-action-pathways-map-route-from-covid-19-recovery-to-resilient-net-zeroeconomy

3 These include (IUCN, 2020): (1) NbS effectively address societal challenges; (2) Design of NbS is informed by scale; (3) NbS result in a net gain to biodiversity and ecosystem integrity; (4) NbS are economically viable; (5) $\mathrm{NbS}$ are based on inclusive, transparent and empowering governance processes; (6) NbS equitably balance trade-offs between achievement of their primary goal(s) and the continued provision of multiple benefits; (7) $\mathrm{NbS}$ are managed adaptively, based on evidence; and (8) NbS are sustainable and mainstreamed within an appropriate jurisdictional context.

${ }^{4}$ The Global Standard can be used to help design interventions, to help verify whether a solution once designed qualifies as an $\mathrm{NbS}$ or not, and to help identify strong candidates for scaling up and identify gaps to work on to transform the intervention into a strong NbS scale-up (IUCN, 2020, pp. 11-12).
} 


\section{Co-benefits}

The key strength of $\mathrm{NbS}$ is that, if well designed and robustly implemented, they can deliver multiple benefits (Austin et al., 2021). Co-benefits ${ }^{5}$ can be derived from NbS addressing societal issues such as water security, food security, human health, well-being and social cohesion, livelihoods, disaster risk-reduction, environmental degradation and biodiversity loss, and climate change mitigation and adaptation (Cooper, 2020b, p. 1; see Figure 1). Co-benefits should be included in the design stage of an $\mathrm{NbS}$ intervention in order to maximise their effects.

\section{There is evidence to show that NbS can be more cost-effective compared to alternative} hard infrastructure-based approaches, especially for adaptation to climate hazards due to the co-benefits they deliver in addition to, for example, reducing climate risk (Kapos et al., 2019 , p. 1). The flexibility of NbS mean they can often address multiple climate challenges and be implemented in multiple sectors; they can complement hard engineering approaches and make up part of an overall adaptation strategy; and they can often be implemented with lower technical inputs (Kapos et al., 2019). The flexibility of ecosystems themselves also means that $\mathrm{NbS}$ can be more easily expanded, altered, adjusted, or even removed than traditional investments, offering a more effective strategy for modifying investments over time in response to (unforeseen) climate impacts (Matthews \& De La Cruz, 2020, p. 19).

Figure 1: The Benefits of Nature-based Solutions

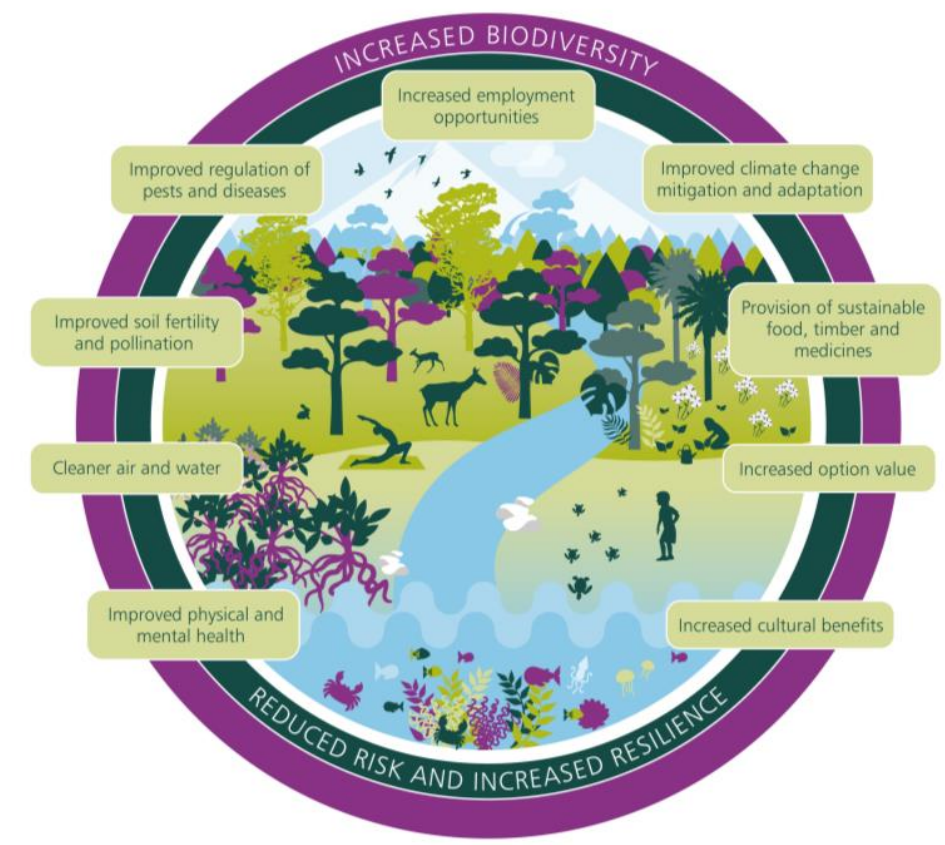

Source: Dasgupta, 2021, p. 457. Open Government Licence v3.0.

Examples of NbS co-benefits include (Dasgupta, 2021 Chapter 19; Cohen-Shacham et al., 2016, p. 7):

- Restoring and sustainably managing wetlands and rivers to maintain or boost fish stocks and fisheries-based livelihoods, reduce the risk of flooding, and provide recreational and

\footnotetext{
${ }^{5}$ Co-benefits represent the additional advantages that come from a project beyond its primary aim (Matthews \& De La Cruz, 2020, p. 14).
} 
tourism benefits.

- Conserving forests to support food and energy security, local incomes, climate change adaption and mitigation, and biodiversity.

- Restoring drylands to strengthen water security, local livelihoods and resilience to climate change impacts.

- Developing green infrastructure in urban environments (e.g. green walls, roof gardens, street trees, vegetated drainage basins) to improve air quality, support wastewater treatment, and reduce stormwater runoff and water pollution as well as improve the quality of life for residents.

- Using natural coastal infrastructure such as barrier islands, mangrove forests and oyster reefs to protect shorelines and communities from coastal flooding and reduce the impacts of sea-level rise.

A 2019 report by the Global Commission on Adaptation called Adapt Now: A Global Call for Leadership on Climate Resilience also highlights the benefits of NbS for climate change mitigation and adaption across different landscapes (see Figure 2). For more in-depth information on different $\mathrm{NbS}$ commonly used for adaptation in relation to specific climate hazards (namely coastal hazards, and hazards linked to intense precipitation, drought, and heat) see Kapos et al. (2019, pp. 19-23).

$\mathrm{NbS}$ also offer "opportunities for encouraging mainstreaming of environmental targets into sectors in policy, business and practice that might not traditionally consider or value the environment, thereby strengthening the potential for strong sustainability in decision making" (Nesshöver et al., 2017, p. 1224).

Figure 2: How different nature-based solutions can work together across landscapes to build resilience

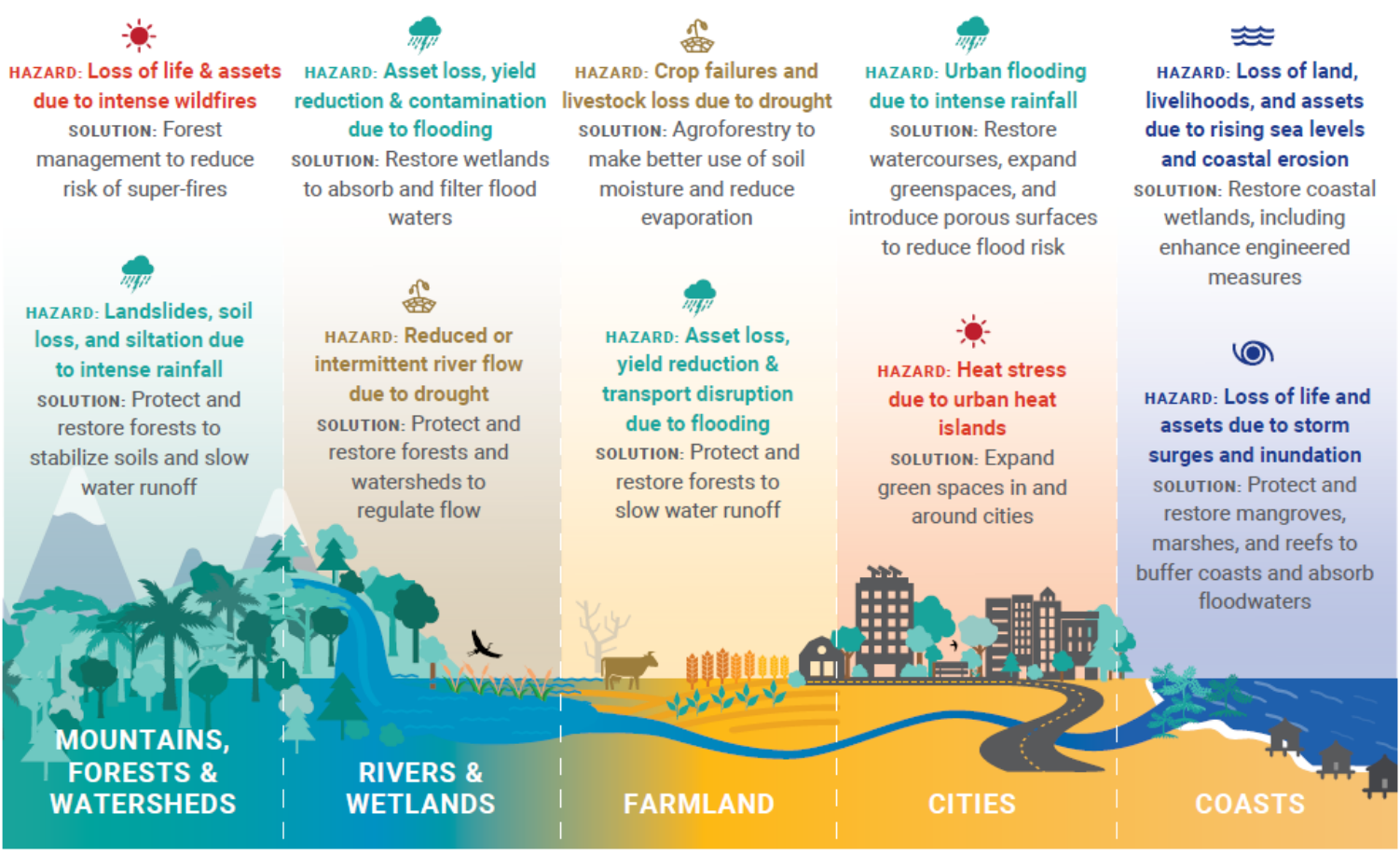

Source: Global Commission on Adaptation, 2019, p. 32. Creative Commons Attribution 4.0 International License. 


\section{Urban areas}

Given the dual pressures of rapid urbanisation and increasing vulnerability to climate change risks in the world's cities, NbS is increasingly being promoted and incorporated into urban adaptation plans (Kapos et al., 2019, p. 27). In particular, tree planting and creating green spaces are being flagged in adaptation plans. However, the availability of land is a key barrier to the use of $\mathrm{NbS}$ in cities; clear prioritisation of green infrastructure allocation is needed to realise $\mathrm{NbS}$ (Kapos et al., 2019). However, this also raises huge justice and equity issues, especially around land tenure rights of local communities (especially poor and marginalised people), distribution of benefits and power dynamics (Bush \& Doyon, 2019). Justice dimensions are not always explicitly considered, and tensions often exist between the ideal of sustainable and just cities and the reality of urban NbS being partly reliant on the existing power structures they seek to influence (van der Jagt et al., 2021). Hence, there is a need for NbS to take a context-sensitive approach, with continual consideration of justice issues.

\section{Increasing green space and planting trees in urban areas can help with cooling and flood abatement while mitigating air pollution, providing recreation and health benefits and sequestering carbon (Seddon et al., 2021, p. 1519). Raymond et al. (2017) include the improvement of place attractiveness, of health and quality of life, and creation of green jobs as co-benefits of $\mathrm{NbS}$ in urban areas. For example, China in 2013 established the concept of the "sponge city" to tackle flooding and water scarcity in its cities. More than 120 pilot projects in 30 cities have been approved that use combined green and grey solutions that prioritise natural drainage, increasing wetlands and the creation of permeable surfaces to absorb rain (GCA, 2021, p. 91).}

Given the complexities of urban environments, a variety of actors and stakeholders from different sectors and policy areas across multiple levels will need to come together to develop holistic strategies to achieve successful delivery of ecosystem services and NbS. Key organisations working in and promoting NbS for adaptation in urban areas include GIZ, IUCN, and ICLEI (Local Governments for Sustainability) (Kapos et al., 2019, p. 27). Landscape and urban planning have been identified as important instruments to enhance the consideration and uptake of $\mathrm{NbS}$ in urban areas, helping to address key trade-offs across temporal, spatial, functional, and social equity aspects (Bush \& Doyon, 2019; Raymond et al. 2017). Although knowledge gaps remain in relation to how the inherently anthropocentric urban planning processes can give voice to nonhuman nature (Bush \& Doyon, 2019).

\section{Trade-offs and concerns}

It is important for policymakers, practitioners, and researchers to consider the trade-offs as well as the synergies of $\mathrm{NbS}$ (Seddon et al., 2021). Concerns around the use of NbS in the context of climate change include: focus on NbS use to excuse the continued use of fossil fuels and business as usual; an over-emphasis on tree planting as a 'silver-bullet' solution to climate change, also distracting us from the urgent need to protect and connect a wide range of intact ecosystems across landscapes and seascapes (Seddon et al., 2021. 1521). NbS can provide both mitigation and adaptation to climate change benefits, but different NbS vary in the extent to which they support biodiversity, which in turn affects their resilience (their capacity to resist and recover from disturbances) (Seddon et al., 2020, p. 2). For example, NbS that do not utilise ecological principles and support biodiversity (e.g. non-native monocultures) are more vulnerable to environmental change in the long term and may also produce trade-offs among ecosystem 
services (Seddon et al., 2020, p. 2). NbS are also vulnerable to co-option by powerful interests (van der Jagt et al., 2021).

There are also limits to what ecosystems can achieve and these need much better identification (WWAP/UN-Water, 2018, p. 18). These issues can in part be related to the uncertainties in the underlying science of $\mathrm{NbS}$ and climate change, including the limited contexts in which the broader benefits of NbS have been demonstrated (Chausson et al., 2020; Seddon et al., 2021). Miscommunications about the mitigation potential of working with nature have also contributed to these issues (Seddon et al., 2021) - highlighting the need to be clear about the benefits and trade-offs of $\mathrm{NbS}$.

$\mathrm{NbS}$ also tend to be highly context-specific, which adds to the uncertainties around their effectiveness in different locations and for differing climate hazard severity. This compounds the inherent uncertainty in climate projections and hazard estimation. Furthermore, some $\mathrm{NbS}$ for mitigation and/or adaptation can be climate-sensitive themselves, further adding to this complexity and uncertainty (Seddon et al., 2020). This highlights the critical need to understand and manage for ecosystem-wide resilience (Kapos et al., 2019, p. 1).

It is critical that $\mathrm{NbS}$ are well thought out and context specific, utilising both scientific and local/indigenous knowledge. Careless or poorly planned or implemented NbS could result in undesirable (and unintended) impacts on-site, due to imbalance in natural resources consumption or the use of harmful materials (Somarakis et al., 2019, p. 65). Impacts can be environmental and social.

Who accrues benefits and who does not from an NbS intervention is also key, with potential trade-offs between different land uses (and the people depending on them), different population groups, upstream and downstream areas, and people using different parts of a connected ecosystem (Reid et al., 2019, p. 13). For example, upstream forest management or activities to recharge groundwater levels in Nepal provide benefits around agriculture or water provision that largely accrue downstream. In contexts where rights are weak (in particular land tenure), there are also concerns that NbS may infringe on these rights and "be implemented in the absence of community consent or cause adverse social consequences" (Seddon et al., 2021, p. 1521). It is likely that existing inequalities in power and access will be exacerbated by NbS if these are not explicitly incorporated in project design.

\section{Other issues to consider include:}

- Some NbS can take time to deliver their main benefits and co-benefits in full (Kapos et al., 2019).

- Benefit-cost ratios for NbS can also be variable over time due to delays in accrual of benefits (Kapos et al., 2019, p. 18).

- Justice considerations. E.g. land availability and spatial trade-offs for $\mathrm{NbS}$, especially in urban areas (Bush \& Doyon, 2019).

- Climate finance is also increasingly being diverted towards $\mathrm{NbS}$; hence it is key to ensure that the concept is "not misappropriated, co-opted or corrupted" (Seddon et al., 2021, p. 1521). 
To deliver sustainable benefits to society $\mathrm{NbS}$ must be led by the following guiding principles (Seddon et al., 2021, p. 1518): 6

1. NbS are not a substitute or alternative for the rapid phase out of fossil fuels and decarbonising of the economy.

2. NbS should involve protection, restoration and sustainable management of a wide range of ecosystems on land and in the sea, not just forests.

3. NbS are implemented with the full engagement and consent of Indigenous Peoples and local communities in a way that respects their cultural and ecological rights; and

4. NbS should be explicitly designed to provide measurable benefits for biodiversity.

\section{Evidence on effectiveness}

Despite some uncertainties, evidence of effectiveness to support the use of $\mathrm{NbS}$ is increasing and can be found worldwide. The Nature-Based Solutions Initiative, based at the University of Oxford, has developed an Evidence Tool which draws together global peerreviewed evidence linking NbS to climate change adaptation outcomes. ${ }^{7} \mathrm{~A}$ number of international organisations and donors are also working on $\mathrm{NbS}$ and expanding the evidence base. The World Resources Institute (WRI) has a NbS for adaptation element to its Climate Resilience programme, which aims to accelerate the uptake of NbS by countries and cities, including identifying appropriate metrics and catalysing investment. ${ }^{8}$ The Dasgupta Review (2021) presents some of the emerging evidence when comparing $\mathrm{NbS}$ with engineering solutions (see Table 1 below).

\section{Global Commission for Adaptation (GCA)}

Findings from a 2019 review of the evidence on $\mathrm{NbS}$ for adaptation undertaken for the GCA include (Kapos et al., 2019, p.2):

- Most NbS experience is evident in safeguarding food security and rural livelihoods in the face of drought or intense rainfall hazards.

- There is increasing evidence on the use of NbS for adaptation in cities to address e.g. flooding, drought, and heat island effects, through re-naturing water courses and creating urban green spaces.

- The use of $\mathrm{NbS}$ for adaptation to enhance the resilience of infrastructure are more limited but growing.

- There is increasing experiences in coastal ecosystem restoration to protect investments from damage due to storm surges and flooding and in watershed restoration to reduce the impacts of intense rainfall and sedimentation on hydroelectric facilities.

- There is less experience overall in using $\mathrm{NbS}$ for adaptation in industry and supply chains than in other sectors, although this is also growing.

\footnotetext{
${ }^{6}$ See also Nature-based Solutions to Climate Change: Key messages for decision makers in 2021 and beyond, https://nbsguidelines.info/ [accessed 29/04/2021]

7 See https://www.naturebasedsolutionsevidence.info/ [accessed 30/04/2021]

8 Information taken from https://www.wri.org/initiatives/nature-based-solutions-adaptation [accessed 04/05/2021]
} 
Table 1: Examples of economic indicators from NbS (reported by Dasgupta, 2021)

\section{Intervention}

Net social economic benefits of $€ 1,400 \pm 600$ ha $^{-1} \mathrm{yr}^{-1}$ from 8 restored rivers over unrestored rivers (through increase in cultural and regulating services, provisioning services remained the same)

Ecosystem-based adaptation was more effective than hard infrastructure when looking at flood alleviation in two river catchments:

- Highest benefit:cost ratio was from planting riparian buffer vegetation BCR between 2.8 and 21.6.

- Highest net present values (NPV) were from upland reforestation, between US\$6.1-US\$48.9 million.

- River dredging (hard infrastructure intervention) provided high benefits but accrued only by a few, and costs were high in relation to benefits.

\section{Location and source}

\section{Europe}

(Vermaat et al., 2016)

Fiji

(Daigneault, Brown \&

Gawith, 2016)
Analysis of capital investments and maintenance cost of ecosystem restoration shows benefit cost ratios ranging from 0.5:1 (coral reefs and coastal systems, worst-case scenario) to as high as 35:1 (grasslands, best-case scenario) and reported that most of the studies analysed provided net benefits

Meta-analysis (capital investment and maintenance costs (94 studies) compared to monetary value of ecosystem services provided (225 studies))

(De Groot et al., 2013)

Salt marshes and mangroves can be two to five times cheaper than submerged breakwaters designed to reduce wave heights by up to half a metre. $\mathrm{NbS}$ provide other benefits, including reduced damage from storm events, reduced erosion, and reduced costs of coastal defense.
Meta-analysis (52 projects)

(Narayan et al., 2016)

NbS compared favourably with engineered solutions; average benefit cost ratios for NbS were above 3.5. Cost-effective coastal adaptation measures could prevent US $\$ 57-101$ billion in losses; NbS could avert more than US $\$ 50$ billion of these costs.

Net wealth increase in real terms of around US $\$ 33$ per person (2005 \$) over 20 years, due to the protection benefits of the creation of a $100 \mathrm{~km}^{2}$ coastal marsh wetland.

$\sim 40$ jobs created per US $\$ 1 \mathrm{~m}$ invested in $\mathrm{NbS}$, because requires relatively low training and education requirements, are fast to establish and require relatively little produced capital for each worker (around 10 times the job creation in fossil fuel industry). There is evidence that about $70 \%$ is invested or spent locally, resulting in large economic multipliers.

Ecosystem restoration and avoided land and ocean use expansion could deliver 11 million more jobs by 2030 , through various forms of business opportunities. Incorporating nature elements not built environments to mitigate against extreme events could create an additional 4 million jobs by 2030 .

\section{Gulf of Mexico, US}

(Reguero et al., 2018).

Louisiana, USA

(Barbier, 2016)

Global

(Levy, Brandon \&

Stuart, 2020; ILO, 2012, 2020)

Global

(World Economic

Forum, 2020) 


\section{The 'Ecosystem-based approaches to climate change adaptation: strengthening the evidence and informing policy' project ${ }^{9}$}

Reid et al. (2019), using data from this project, explore evidence on EbA effectiveness (i.e. NbS effectiveness) at 13 case study sites in 12 countries. Reid et al. (2019) emphasise how most EbA projects (and NbS more broadly) lack experimental counterfactuals to compare them with to assess effectiveness, many also lack robust scientific data to measure factors such as ecosystem service provision. Reid et al. (2019) use capturing perceptions in the absence of such quantitative data, as a useful way to assess EbA effectiveness and capture information that quantitative methods do not. They found that all case studies were thought to provide a multitude of social co-benefits, including livelihood or health improvements and provision of water for productive use. Furthermore, perceived improvements in resilience, adaptive capacity and vulnerability arising from EbA project activities tended to accrue among particularly vulnerable groups of people, notably women (Reid et al., 2019, p. 8).

\section{A 'whole-ecosystem-approach'}

It is essential to take a 'whole-ecosystem-approach' when implementing $\mathrm{NbS}$. Using a landscape approach that encompasses protection, restoration, and sustainable management of a wide range of ecosystems and their dynamics, but tailored to the local geographic context, can optimise the benefits of $\mathrm{NbS}$ (Austin et al., 2021). Hence, transformative changes in policy, land use planning and financial instruments that work with $\mathrm{NbS}$ at the landscape scale are needed to realise this. Including local people and indigenous knowledge is also key to the effectiveness of $\mathrm{NbS}$. NbS should be managed by, or in partnership with, local communities to ensure the legitimacy and long-term stewardship of NbS (Austin et al., 2021, p. 2).

\section{Cost-effectiveness}

Evidence is also growing on the cost-effectiveness of NbS compared to engineered alternatives, however, measuring and accounting for the full array of benefits from NbS in metrics has proven difficult (see sub-section on quantifying benefits) (Seddon et al., 2020). There is a growing consensus among practitioners that a combination of green and grey interventions may be the best solution in many contexts; these synergies may also help address diverging stakeholder needs (Seddon et al., 2020, p. 8).

\section{Design and implementation issues and barriers}

Despite the growing attention and evidence base for $\mathrm{NbS}$, measuring effectiveness remains difficult, and intentions (or commitments to $\mathrm{NbS}$ ) have yet to fully translate into measurable, evidence-based targets for $\mathrm{NbS}$ and action on the ground (Chausson et al., 2020). NbS also face a number of barriers to their use and scale-up. These include lack of awareness and/or understanding of the critical role of natural assets in underpinning social and economic resilience and of NbS approaches, and associated entrenched attitudes and norms (Kapos et al., 2019, p. 2). Lack of accessible funds to invest in and scale-up NbS is a key barrier.

\footnotetext{
9 This seven year project implemented in Asia, Africa and Central and South America by IIED, IUCN and the UN Environment World Conservation Monitoring Centre (UNEP-WCMC) was funded by the International Climate Initiative. For more information see https://www.iied.org/ecosystem-based-approaches-climate-changeadaptation [accessed 30/04/2021]
} 
Furthermore, the disjointed way adaptation is often planned and executed undervalues or ignores the many benefits of working with nature (Global Commission on Adaptation, 2019, p. 31).

Other key challenges include (Kapos et al., 2019, p. 2; Reid et al., 2019, p. 13):

- the mismatch between long-term climate change impacts and short-term governance and decision-making;

- regulatory environments and governance challenges relating to the cross-sectoral and multi-scale nature of $\mathrm{NbS}$, that influence the attractiveness and feasibility of using $\mathrm{NbS}$;

- not knowing how to deal with ecosystem and climate uncertainty;

- technical challenges and gaps in capacity that impede design and wider implementation; perceived investment risk;

- limited or poorly consolidated evidence base on $\mathrm{NbS}$ effectiveness to help make the (business) case for working with nature.

Cohen-Shacham et al. (2016) highlight that a major obstacle to NbS is the lack of operational clarity for many NbS approaches. To help scale-up NbS implementation and strengthen their impact, the IUCN have produced a set of Global Standards to unify NbS approaches (IUCN, 2020).

\section{Scale, context and expectations}

$\mathrm{NbS}$ are often complex, being multifunctional, working at multiple scales and varying over time. The dimensions related to NbS impacts can entail various aspects, such as spatial, temporal, ecological, social, jurisdictional, cultural, or economical (Somarakis et al., 2019, p. 58).

The spatial scale at which NbS operate is important - with many arguing that NbS should operate at the same scale as the ecosystems, in order to achieve impact (Kapos et al., 2019). This may be key to the success of an intervention (such as restoration), however, ecosystem scales, e.g. river basin, do not necessarily overlap with land ownership, administrative boundaries and political authority (Kapos et al., 2019). Working at the ecosystem scale also entails working with a broader range of stakeholders, and $\mathrm{NbS}$ also need to consider the social and economic contexts in which they are set (WWAP/UN-Water, 2018). Scaling up NbS is important if benefits are to extend beyond the project level (Reid et al., 2019, p. 71). However, there is high variability and variation in how ecosystems behave - requiring site-specific knowledge. Biodiversity considerations and links to NbS are complex and also need to be carefully considered to avoid unintended consequences and trade-offs (Nesshöver et al., 2017).

These factors make designing, implementing and measuring the effectiveness and impacts of $\mathrm{NbS}$ even more complicated. NbS should be explored holistically, i.e. considered at different scales (temporal, spatial, social, etc.) - to critically evaluate all an NbS' potential consequences (Somarakis et al., 2019). For example, introducing trees in cities is likely to bring benefits such as carbon sequestration and the decrease of heat island effect, but, at the same time it, may create allergic reactions, and increase fire risks. Context is hence key (Somarakis et al., 2019).

One of the key challenges with the NbS framework is where to draw the line as to what is considered as 'nature' or 'natural' (Nesshöver et al., 2017, p. 1220). This highlights the need 
for each case to make explicit its rationale and particular interpretation of NbS. Nesshöver et al. (2017, p.1220) also highlight that the terminology of 'solutions' can be misleading in NbS as it can lead to assumptions that problems and needs are clear and agreed upon within a system, when in reality issues pertaining to biodiversity and ecosystem management are complex and (often) contested.

There is a need to both better recognise connections within and between societies and ecosystems and accept uncertainty. Moderating the expectations placed on $\mathrm{NbS}$ is also important, it should not be expected for NbS to be cheap and easy, especially in the short-term (Nesshöver et al., 2017).

\section{Quantifying benefits}

Valuing ecosystem services is important in making a business case for investment in NbS (Cohen-Shacham et al., 2016). An often overstated assumption about NbS is that they are 'costeffective', whereas WWAP/UN-Water (2018, p. 18) highlight that this should be established during an assessment, including consideration of co-benefits. Communicating the value of ecosystems and $\mathrm{NbS}$ to policy-makers is also key. However, it has proven difficult to measure the effectiveness of many NbS due to the complexity and multi-dimensionality of the problems being addressed, the multifunctionality of interventions and the multiple spatial and temporal scales of co-benefits (Seddon et al., 2020).

Few frameworks exist for assessing the value of co-benefits of NBS and to guide crosssectoral project and policy design and implementation (Raymond et al., 2017). Assessments also often fail to fully consider trade-offs (Seddon et al., 2020). The lack of clear and consistent metrics makes it difficult for developing countries, project developers, institutions, and investors to appraise and compare NbS options against other investment options; thus, they often are not prioritised (Swann et al., 2021). Reid et al. (2019, p. 10) in their review of the effectiveness of 13 $\mathrm{NbS}$ projects, found that 11 were perceived by stakeholders as delivering cost-effective ecosystem based adaptation measures. However, they noted that projects tended to fare worse against alternative options in terms of cost-effectiveness when they required high initial investments, were evaluated using high discount rates that penalise benefits that accrue in the long term, or where many of the co-benefits were non-monetary.

The Dasgupta Review (2021) highlights that the cost of restoration directly increase with the level of degradation in the ecosystem, as does the risk of these investments. Given the levels of uncertainty and the inability of markets to sufficiently respond (especially in the presence of tipping points), Dasgupta recommends a role for precautionary policy intervention by governments and regulators towards conserving and protect existing ecosystems before they become overly degraded (see Figure 3). 


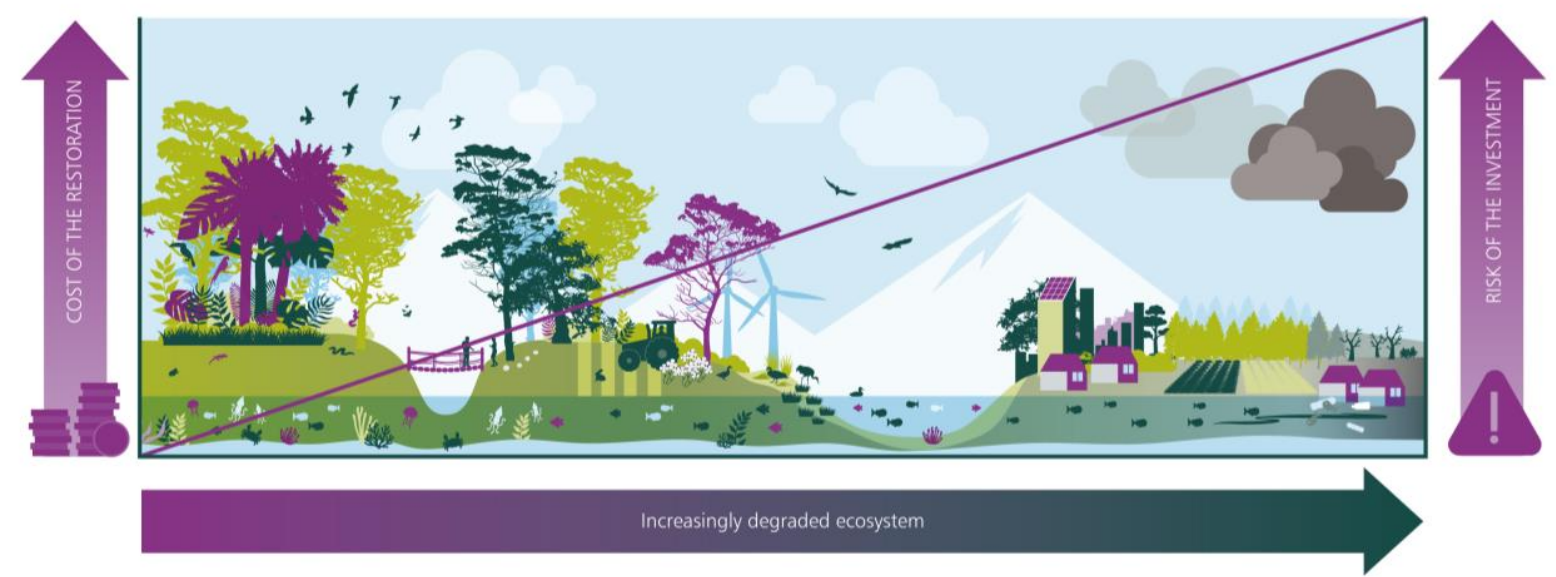

Source: Dasgupta, 2021 [https://www.flickr.com/photos/191878461@N05/]. Open Government Licence v3.0.

Cost-benefit analyses do not reflect or capture the co-benefits of $\mathrm{NbS}$. Consequently, Raymond et al. (2017, p. 22) encourage going beyond cost-benefit analysis to assess the different elements of $\mathrm{NbS}$ effectiveness. There is a need for further research into co-benefit analyses across scales and across multiple stages of NbS implementation, as well as coevaluation across multiple challenges (Raymond et al., 2017). Robust metrics that go beyond monetary values are needed to better reflect these benefits and assess the effectiveness of a wide range of $\mathrm{NbS}$ for carbon sequestration, water regulation, disaster risk reduction, biodiversity and human wellbeing (including poverty alleviation and socioeconomic development) (Austin et al., 2021; Reid et al., 2019; Seddon et al., 2020). Seddon et al. (2020) emphasise that what counts as effective differs depending on the perspectives and needs of those involved. They argue that the dynamic and complex nature of social-ecological systems means that simple standardised metrics of NbS effectiveness that fully capture these complex dimensions are unlikely to be found. Instead, a suite of context-specific metrics is needed (Seddon et al., 2020).

\section{Full consideration of co-benefits, whether through monetary valuation of ecosystem} services or other approaches, can shift the balance in cost-benefit analysis (Kapos et al., 2019, p.17). And these tend to highlight the advantages of hybrid or mixed approaches, where $\mathrm{NbS}$ for adaptation approaches are used to increase the effectiveness or reduce the cost of engineered approaches.

\section{Equity}

There are a number of equity issues related to $\mathrm{NbS}$. Equity and human rights considerations are crucial to climate action, especially in low-income countries. Here NbS to protect carbon sinks and biodiversity may result in increased poverty and restricted access to natural resources by marginalised groups. Hence, key factors that will affect the outcomes and perceived legitimacy of $\mathrm{NbS}$ are land ownership and governance (Austin et al., 2021, p. 2). This highlights equity concerns around some $\mathrm{NbS}$ and uneven distribution of benefits and costs, and questions of who benefits, how benefits are shared, and who accrues the benefits and who loses out. Equity concerns have not always been well-addressed in the literature related to NbS (Bush \& Doyon, 2019). 


\section{Stakeholder engagement}

Stakeholder engagement, especially with local communities, is key for the success of NbS as they often rely on these actors to implement and manage interventions (WWAP/UNWater, 2018). Early engagement is particularly critical to help develop a sense of co-ownership of the $\mathrm{NbS}$ and to shape it to maximise its potential benefits and understand any concerns (Somarakis et al., 2019). Strong political support and leadership is also important for successful implementation and to facilitate cooperation across multiple stakeholders at scale (Kapos et al., 2019).

This cooperation and engagement can be difficult to achieve, especially as there is often a lack of knowledge and information available about $\mathrm{NbS}$ and what it can offer. Given the reliance on local actors for the success of many $\mathrm{NbS}$, understanding which stakeholders might stand to lose (or perceive that they will lose) and any potential equity concerns are critical in securing social license to operate by the community and need to be prioritised and addressed (Somarakis et al., 2019, p. 130; WWAP/UN-Water, 2018, p. 18). Other issues can be around trust, transparency, power dynamics and equity among stakeholders as well as with the NbS intervention itself.

\section{Finance}

Only a relatively small amount of public international funding flows to $\mathrm{NbS}$ for adaptation; in 2018 , this accounted for only US $\$ 3.8-8.7$ billion, or approximately $0.6-1.4 \%$ of total climate finance flows and $1.5-3.4 \%$ of public climate finance flows (Swann et al., 2021). Many struggle to quantify, value and articulate the multiple benefits of $\mathrm{NbS}$ in financial terms, which can in turn hinder the development of a strong business case and inhibit the development and financing of a robust pipeline of NbS-related investments (Somarakis et al., 2019, p. 22; Swann et al., 2021).

Barriers in relation to financing NbS include: limited or restricted data and research on benefits; a lack of clear financing instruments and standardised finance models; a lack of policy and financial frameworks; barriers in the enabling environment that stop NbS being considered on an equal footing with grey infrastructure; and, traditional economic, financial, and engineering cost-performance systems that favour single-purpose grey infrastructure over $\mathrm{NbS}$ investments (OECD, 2020; Cooper \& Matthews, 2020, pp. 6-8; Somarakis et al., 2019).

The dynamic and complex nature of natural systems that can both vary spatially and over time creates uncertainty, which can lead to concerns over the performance reliability of NbS (OECD, 2020). This dynamism and a lack of robust performance data complicates assessing the technical performance of NbS projects, how they might interact with grey infrastructure if it is part of a hybrid project, and developing solid predictions about the level of service provided - reinforcing investor's preference for business-as-usual infrastructure solutions and perception of $\mathrm{NbS}$ as high risk (OECD, 2020).

The longer timeframes for realising benefits from $\mathrm{NbS}$ relative to grey infrastructure can lead to investors and policy-makers defaulting to grey infrastructure. Investors often evaluate projects over the lifetime of the financing vehicle as opposed to the operational lifetime of the project (OECD, 2020). Benefits from NbS may also change over time.

The context-specific nature of many NbS can also affect investor confidence (OECD, 2020). Technical and practical aspects (such as continuous low-level maintenance needs) can also act 
as barriers for increasing investment in NbS (OECD, 2020). Quantifying and valuing the benefits and co-benefits of $\mathrm{NbS}$ and translating them into revenue streams is also difficult (see above sub-section). Furthermore, many of the benefits associated with NbS cannot be capitalised by any one organisation, creating externalities, which impact on risk sharing and attractiveness of investment (Seddon et al., 2020).

\section{Awareness raising and technical guidance to support decision- making}

Decision makers and practitioners also often lack the expertise to successfully address possible trade-offs and make optimal use of available NbS (Somarakis et al, 2019). This is further hampered by the limited knowledge regarding designing, implementing, and maintaining $\mathrm{NbS}$ or quantifying their benefits and co-benefits. Decision makers also often lack the information needed to adequately evaluate and compare green infrastructure options to business-as-usual (Browder et al., 2019).

It is critical to convince decision-makers of the benefits and value of investing in $\mathrm{NbS}$ in the long-term. The development of the Global Standard by IUCN is an important step (Austin et al., 2021). Working with champions and leaders who can motivate and mobilise their peers is key in this. Champions and leaders can be at the government level or in a local community (CohenShacham et al., 2016, p. 25). The Global Commission on Adaptation (2019) recommend raising awareness and understanding of the value of nature for climate adaptation in both Governments and companies. Natural capital methodologies are powerful tools to help value nature's benefits, raise understanding, and inform planning processes. But continuing to gather evidence of what works and what does not, sharing of experiences and technical knowledge across sectors, and considering both indigenous and scientific knowledge are also key to increase understanding (Global Commission on Adaptation, 2019, p. 32). In particular, embedding NbS into adaptation planning and policy using participatory planning processes is critical.

Local knowledge is particularly important for NbS, especially from indigenous communities that have adaptive capacity embedded in their traditional knowledge systems. For example, participatory planning with diverse stakeholders on the coast of northern Java, Indonesia has restored a $20-\mathrm{km}$ stretch of coastal mangroves, introduced sustainable aquaculture, and reduced groundwater extraction resulting in increased resilience for 70,000 people, with additional carbon storage, biodiversity, and fisheries benefits (Global Commission on Adaptation, 2019, p.33).

\section{Financing and the enabling environment}

\section{Enabling environment}

$\mathrm{NbS}$ need to be embedded into the existing policy mix and integrated into national and subnational government planning processes. Due to the multiple implementation barriers faced by $\mathrm{NbS}$, they require proactive and innovative policy interventions (at all levels - local, regional, national etc) in order to be mainstreamed (Somarakis et al., 2019, p. 22). However, the majority of current planning processes and regulatory and legal environments were developed largely with grey-infrastructure approaches in mind, and often hinder or prevent the consideration of NbS projects (Matthews \& De La Cruz, 2020; Somarakis et al., 2019, p. 22). Hence, decision- 
making processes around planning, implementing, operating, and financing infrastructure will need to be adapted if $\mathrm{NbS}$ are to be applied consistently and considered on an equal footing with grey infrastructure (OECD, 2020). Promoting NbS more effectively through existing frameworks and identifying where and how NbS can support existing planning approaches at different levels is also important. Particularly crucial is national legislation to facilitate the implementation of $\mathrm{NbS}$ at the local level (Matthews \& De La Cruz, 2020). NbS can also benefit and help achieve the harmonisation of policies across economic, environmental, and social agendas in fragmented policy landscapes.

The institutional context will also need to evolve at the same time to enable the necessary shifts to take place (Nesshöver et al., 2017). Emerging technical and professional standards will help to increase the acceptability of NbS within financial institutions - including the IUCN Global Standard (Kapos et al., 2019). Nesshöver et al. (2017, pp. 1220-1221) highlight the following key elements for the operationalisation of the NbS concept, which are also key aspects to help define what makes NbS sustainable:

- Dealing with uncertainty and complexity: Consider how the 'solution' deals with the complexity of problems, which cannot be simply broken down to 'easy' solutions.

- Stakeholder engagement: Consider how to ensure the involvement of all relevant stakeholders, taking into account social cohesion and equity.

- Ensuring the sound use of multi- and transdisciplinary knowledge: NbS projects will need to be combined with an increase of interdisciplinary work across scientific domains (especially social science, as well as natural science). Important to consider to what degree 'solutions' rely on technical/physical types of innovation, and whether intellectual and social innovations are considered.

- Developing common understanding of multifunctional solutions, trade-offs and natural adaptation: Framing of nature is challenging; and the range and nature of the problems to be 'solved' need specification on a case-by-case basis. Most NbS will likely include some degree of alteration and/or 'design' of nature (e.g., trade-offs by favouring/choosing one ecosystem service over another, by selecting certain assemblies of species). It is therefore important to try to consider all the possible pros and cons of an intervention. Complexity in ecosystem responses also presents considerable challenges in NbS, and requires flexible and transparent models of key structures and processes that can use scientific and practical knowledge, and incorporate new knowledge as it emerges.

- Evaluate and monitor for mutual learning: The development of adequate measures of progress and success towards agreed goals (including ecological, social and economic effectiveness of an intervention) is a final key element for $\mathrm{NbS}$. These are often difficult to set for $\mathrm{NbS}$ to capture the complexities of the problems being addressed, including differing spatial scales (e.g. local to regional, national to global) and time-spans.

To understand the benefits and trade-offs, each site considered for NbS must be assessed individually, and in its landscape context, so that appropriate action can be taken (Nesshöver et al., 2017). One of the key factors to implementing NbS successfully is stakeholder engagement and buy-in from all actors, particularly landowners and the local community. This is best achieved by developing projects with stakeholders from the outset (Nesshöver et al., 2017; Kapos et al., 2019; Swann et al., 2021). The development of multilateral consortia of close partnerships between different organisations and stakeholders seem to be crucial to the provision of long-term 
investments in ecosystems (Seddon et al., 2020). To realise the full benefits of NbS they need to be implemented within a systems-thinking framework that accounts for multiple ecosystem services and recognises trade-offs from multiple perspectives (Seddon et al., 2020, p. 9).

\section{Financing}

Increasing investment requires national and local governments to reorient fiscal policies, subsidies and investments around natural environment objectives (Global Commission on Adaptation, 2019, p. 34). There is a need for increased investment in NbS; currently donor sources of funding for NbS do not align with needs (Swann et al., 2021). Well-designed, innovative funding mechanisms could be instrumental for scaling-up $\mathrm{NbS}$, and there are a number of potential new financing options available (Austin et al., 2021). For example, payments for ecosystem services (PES), tax incentives, green bonds, resilience bonds, insurance schemes, and water user fees. Blended public and private finance opportunities are also being explored. Costa Rica has successfully deployed PES schemes to conserve natural assets (Global Commission on Adaptation, 2019, p. 34). Austin et al. (2021, p. 5) suggest stacking of multiple benefits for climate, biodiversity, and other services, financed by different beneficiaries and supported by a greater range of multi-sectoral legislative or policy instruments can make NbS more investable.

\section{A number of international organisations are stepping up their support for $\mathrm{NbS}$ for} adaptation, especially in the context of disaster risk reduction. The World Bank and the Global Facility for Disaster Reduction and Recovery (GFDRR) are investing in NbS for adaptation, with just over 1 in 10 of the World Bank's disaster risk management projects now containing some element of $\mathrm{NbS}$. Other organisations making substantial investments in $\mathrm{NbS}$ in developing countries include: UN Environment, UNDP, IUCN and The Nature Conservancy (TNC), utilising financing from the GEF, Green Climate Fund (GCF), and others (Kapos et al., 2019, p. 17). The EU, Asian Development Bank, and the International Fund for Agricultural Development (IFAD) are also among the largest multilateral donors (Swann et al., 2021). Germany is a major bilateral donor of EbA (Kapos et al., 2019, p. 17). Other major bilateral funders for NbS for adaptation include UK, Japan and Sweden (based on 2018 data) (Swann et al., 2021). The majority of public funding in 2018 came through grants; around $50 \%$ of total public $\mathrm{NbS}$ for adaptation funding went to countries in sub-Saharan Africa and Central Asia (Swann et al., 2021).

\section{New sources of finance and support for NbS are emerging: ${ }^{10}$}

- The Global Ecosystem-based Adaptation Fund, supported by Germany and implemented by UNEP and IUCN, aimed at providing seed funding to non-state actors to catalyse the scaling up of EbA was announced at the 2021 Climate Adaptation Summit with an initial capitalisation of EUR 15 million, and the first call for proposals expected in 2021.

- The Special Climate Change Fund (SCCF) of the GEF approved a US $\$ 2$ million novel project to support monetary valuation of Nature-Based Infrastructure (NBI), with the objective of demonstrating its economic case and catalysing more public and private investment.

\footnotetext{
10 Information taken from https://www.cas2021.com/outcomes/ae-nbs-outcomes [accessed 04/05/2021]
} 
- A Project Preparation Facility (PPF) has also been designed that will build a pipeline of bankable city-led $\mathrm{NbS}$ projects for climate adaptation and human wellbeing that are positioned to access large-scale infrastructure finance and capital markets.

\section{Knowledge gaps}

\section{Despite the rapid uptick in research and peer-reviewed articles on $\mathrm{NbS}$ in recent years,} knowledge gaps still exist regarding concepts and methods of planning $\mathrm{NbS}$ in practice. There is still a lack of robust and impartial assessments of current NbS experiences, and knowledge gaps persist in relation to site specific knowledge of field deployment of NbS; timescales over which benefits are seen and experienced; cost-effectiveness of interventions compared to or in conjunction with alternative solutions; and integrated assessments considering broader social and ecological outcomes (Chausson et al., 2020, p. 6134; Cooper, 2020b, p. 22; WWAP/UN-Water, 2018). Other knowledge gaps include:

- How to integrate and mainstream NbS into urban policies, planning processes, and decision-making mechanisms (Somarakis et al., 2019).

- The question of how to combine NbS with biodiversity conservation at scale also needs to be tackled (GCA, 2021, p. 94).

- The evidence base for different $\mathrm{NbS}$ also vary greatly. For example, in the peer-reviewed papers identified by the Nature-Based Solutions Initiative linking NbS to climate change adaptation outcomes, certain types of ecosystems, climate change impacts, and interventions dominate in the studies.

There is a need for increased knowledge to support decision-making (Kapos et al., 2019), with research programmes with multiple stakeholders and sharing of lessons learned. In particular, more holistic cost-benefit analysis and common criteria/methods for fully capturing and measuring benefits and co-benefits are needed (Raymond et al., 2017; WWAP/UN-Water, 2018).

\section{References}

Austin, W., Cohen, F., Coomes, D., Hanley, N., Lewis, S., Luque-Lora, R., Marchant, R., Naylor, L., Queirós, A. M., Savaresi, A., Seddon, N., Smith, A., Smith, P. \& Wheeler, C. (2021). Nature-based solutions for climate change, people and biodiversity. COP26 Universities Network Briefing. https://www.gla.ac.uk/media/Media_790171_smxx.pdf

Barbier, E.B. (2016). 'The Protective Value of Estuarine and Coastal Ecosystem Services in a Wealth Accounting Framework', Environmental and Resource Economics, 64(1), 37-58. https://link.springer.com/article/10.1007\%2Fs10640-015-9931-z

Browder, G., Ozment, S., Bescos, I., Gartner, T. \& Lange, G-M. (2019). Integrating Green and Gray: Creating Next Generation Infrastructure. Washington, DC: World Bank and World Resources Institute. https://files.wri.org/s3fs-public/integrating-green-gray-executivesummary.pdf

Bush, J. \& Doyon, J. (2019). 'Building urban resilience with nature-based solutions: How can urban planning contribute?' Cities, 95, https://doi.org/10.1016/j.cities.2019.102483

Chausson, A., Turner, B., Seddon, D., Chabaneix, N., Girardin, C. A., Kapos, V., ... \& Seddon, N. (2020). 'Mapping the effectiveness of nature-based solutions for climate change 
adaptation.' Global Change Biology, 26(11), 6134-6155.

https://onlinelibrary.wiley.com/doi/full/10.1111/gcb.15310

Cohen-Shacham, E., Walters, G., Janzen, C. and Maginnis, S. (eds.) (2016). Nature-based Solutions to address global societal challenges. Gland, Switzerland: IUCN.

https://www.iucn.org/sites/dev/files/content/documents/2016-036.pdf

Cohen-Shacham, E., Andrade, A., Dalton, J., Dudley, N., Jones, M., Kumar, C., ... \& Walters, G. (2019). 'Core principles for successfully implementing and upscaling Nature-based Solutions.' Environmental Science \& Policy, 98, 20-29. https://doi.org/10.1016/j.envsci.2019.04.014

Cooper, R. (2020a). Biodiversity conservation and restoration, and poverty reduction. K4D Helpdesk Report 773. Brighton, UK: Institute of Development Studies. https://opendocs.ids.ac.uk/opendocs/handle/20.500.12413/15180

Cooper, R. (2020b). Nature-based solutions for water security. K4D Helpdesk Report 813. Brighton, UK: Institute of Development Studies.

https://opendocs.ids.ac.uk/opendocs/handle/20.500.12413/15412

Cooper, R. \& Matthews, J.H. (2020). Water Finance and Nature-based solutions. K4D Helpdesk Report 857. Brighton, UK: Institute of Development Studies.

https://opendocs.ids.ac.uk/opendocs/handle/20.500.12413/15592

Daigneault, A., P. Brown, and D. Gawith (2016), 'Dredging Versus Hedging: Comparing Hard Infrastructure to Ecosystem-Based Adaptation to Flooding', Ecological Economics, 122, 25-35. https://www.sciencedirect.com/science/article/abs/pii/S092180091500467X

Dasgupta, P. (2021). The Economics of Biodiversity: The Dasgupta Review. London: HM Treasury. https://www.gov.uk/government/publications/final-report-the-economics-ofbiodiversity-the-dasgupta-review

De Groot, R.S., Blignaut, J., Van Der Ploeg, S., Aronson, J., Elmqvist, T. \& Farley, J. (2013). 'Benefits of Investing in Ecosystem Restoration', Conservation Biology, 27(6), 1286-1293. https://conbio.onlinelibrary.wiley.com/doi/abs/10.1111/cobi.12158

European Commission. (2015). Towards an EU Research and Innovation policy agenda for Nature-Based Solutions \& Re-Naturing Cities. Final Report of the Horizon 2020 Expert Group on 'Nature-Based Solutions and Re-Naturing Cities'. Directorate-General for Research and Innovation. Luxembourg: EU.

https://espas.secure.europarl.europa.eu/orbis/document/towards-eu-research-andinnovation-policy-agenda-nature-based-solutions-re-naturing-cities

GCA (Global Centre on Adaptation). (2021). State and Trends in Adaptation Report 2020. Building Forward Better from Covid-19: Accelerating Action on Climate Adaptation. Rotterdam: Global Centre on Adaptation. https://www.cas2021.com/documents/reports/20 21/01/22/state-and-trends-in-adaptation-report-2020

Giordano, R., Pluchinotta, I., Pagano, A., Scrieciu, A. \& Nanu, F. (2020). 'Enhancing naturebased solutions acceptance through stakeholders' engagement in co-benefits identification and trade-offs analysis.' Science of The Total Environment, 713, 136552. https://doi.org/10.1016/j.scitotenv.2020.136552

Global Commission on Adaptation. (2019). Adapt Now: A Global Call for Leadership on Climate Resilience. Washington, DC: World Resources Institute. Global Commission on Adaptation. https://openknowledge.worldbank.org/handle/10986/32362 
ILO. (2012). Working Towards Sustainable Development: Opportunities for Decent Work and Social Inclusion in a Green Economy. Geneva: ILO.

https://www.ilo.org/wcmsp5/groups/public/---dgreports/---dcomm/---

publ/documents/publication/wcms_181836.pdf

ILO. (2020). Employment-Intensive Investment Programme (EIIP) Guidance: COVID-19: Job creation through employment-intensive public works programmes.

https://www.ilo.org/wcmsp5/groups/public/---

ed_emp/documents/publication/wcms_743537.pdf

IUCN (2020). Guidance for using the IUCN Global Standard for Nature-based Solutions. A userfriendly framework for the verification, design and scaling up of Nature-based Solutions. First edition. Gland, Switzerland: IUCN. https://portals.iucn.org/library/sites/library/files/documents/2020-021-En.pdf

Kapos, V., Wicander, S., Salvaterra, T., Dawkins, K., Hicks, C. (2019). The Role of the Natural Environment in Adaptation, Background Paper for the Global Commission on Adaptation. Rotterdam and Washington, D.C.: Global Commission on Adaptation. https://gca.org/reports/the-role-of-the-natural-environment-in-adaptation/

Levy, J., Brandon, C. \& Studart, R. (2020), Designing the COVID-19 Recovery for a Safer and More Resilient World. WRI Commentary. https://www.wri.org/insights/designing-covid-19recovery-safer-and-more-resilient-world

Matthews, J.H. \& De La Cruz, E.O. (2020). Protecting and Investing in Natural Capital in Asia and the Pacific: A Practitioner's Guide to Nature-Based Solutions. ADB Report. Manila: Asian Development Bank. https://www.adb.org/projects/documents/reg-50159-001-tacr-3

Narayan, S., Beck, M.W., Reguero, B.G., Losada, I.J., Van Wesenbeeck, B., Pontee, N., Sanchirico, J.N., Ingram, J.C., Lange, G.M. \& Burks-Copes, K.A. (2016). 'The Effectiveness, Costs and Coastal Protection Benefits of Natural and Nature-Based Defences', PLOS ONE, 11(5), e0154735.

https://journals.plos.org/plosone/article?id=10.1371/journal.pone.0154735

Nesshöver, C., Assmuth, T., Irvine, K. N., Rusch, G. M., Waylen, K. A., Delbaere, B., ... \& Wittmer, H. (2017). 'The science, policy and practice of nature-based solutions: An interdisciplinary perspective.' Science of the Total Environment, 579, 1215-1227. https://www.sciencedirect.com/science/article/pii/S0048969716325578

OECD. (2020). Nature-based solutions for adapting to climate-related water risks. OECD Environment Policy Papers, No. 21. Paris: OECD. https://doi.org/10.1787/2257873d-en

Raymond, C., Frantzeskaki, N., Kabisch, N., Berry, P., Breil, M., Nita, M., Geneletti, D., \& Calfapietra, C. (2017). 'A framework for assessing and implementing the co-benefits of nature-based solutions in urban areas.' Environmental Science \& Policy, 77, pp. 15-24, https://doi.org/10.1016/j.envsci.2017.07.008

Reguero, B.G., Beck, M.W., Bresch, D.N., Calil, J. \& Meliane, I. (2018). 'Comparing the Cost Effectiveness of Nature-Based and Coastal Adaptation: A Case Study from the Gulf Coast of the United States', PLOS ONE, 13(4), e0192132.

https://journals.plos.org/plosone/article?id=10.1371/journal.pone.0192132

Reid, H., Hou Jones, X., Porras, I., Hicks, C., Wicander, S., Seddon, N., Kapos, V., Rizvi, A.R. \& Roe, D. (2019). Is ecosystem-based adaptation effective? Perceptions and lessons learned from 13 project sites. IIED Research Report. IIED, London. http://pubs.iied.org/17651IIED 
Seddon, N., Smith, A., Smith, P., Key, I., Chausson, A., Girardin, C., House, J., Srivastava, S. \& Turner, B., (2021). 'Getting the message right on nature-based solutions to climate change.' Global Change Biology, 27(8), 1518-1546.

https://onlinelibrary.wiley.com/doi/full/10.1111/gcb.15513

Seddon, N., Chausson, A., Berry, P., Girardin, C. A., Smith, A., \& Turner, B. (2020).

'Understanding the value and limits of nature-based solutions to climate change and other global challenges.' Philosophical Transactions of the Royal Society B, 375(1794), 20190120. http://dx.doi.org/10.1098/rstb.2019.0120

Swann, S., L. Blandford, S. Cheng, J. Cook, A. Miller, and R. Barr. (2021). Public International Funding of Nature-based Solutions for Adaptation: A Landscape Assessment. Working Paper. Washington, DC: World Resources Institute. https://doi.org/10.46830/wriwp.20.00065

van der Jagt, A., Kiss, B., Hirose, S., \& Takahashi, W. (2021). 'Nature-based solutions or debacles? The politics of reflexive governance for sustainable and just cities.' Frontiers in Sustainable Cities, 2. https://www.frontiersin.org/articles/10.3389/frsc.2020.583833/full

Vermaat, J. E., Wagtendonk, A.J., Brouwer, R., Sheremet, O., Ansink, E., Brockhoff, T., Plug, M., Hellsten, S., Aroviita, J., Tylec, L., Giełczewski, M., Kohut, L., Brabec, K., Haverkamp, J., Poppe, M., Böck, K., Coerssen, M., Segersten, J. \& Hering, D. (2016). 'Assessing the Societal Benefits of River Restoration Using the Ecosystem Services Approach', Hydrobiologia, 769(1), 121-135. https://doi.org/10.1007/s10750-015-2482-z

World Economic Forum (WEF). (2020). New Nature Economy Report II: The Future of Nature and Business. Geneva: WEF. https://www.weforum.org/reports/new-nature-economyreport-ii-the-future-of-nature-and-business

WWAP (United Nations World Water Assessment Programme) /UN-Water. (2018). The United Nations World Water Development Report 2018: Nature-Based Solutions for Water. Paris, UNESCO. https://unesdoc.unesco.org/ark:/48223/pf0000261424/PDF/261424eng.pdf.multi

\section{Key websites}

- Global Centre of Adaptation: https://gca.org/reports/

- IUCN NbS: https://www.iucn.org/resources/issues-briefs/ensuring-effective-nature-basedsolutions

- NbS Initiative, Oxford University: https://www.naturebasedsolutionsinitiative.org/what-arenature-based-solutions/ 


\section{Suggested citation}

Price, R.A. (2021). Nature-based Solutions (NbS) - what are they and what are the barriers and enablers to their use? K4D Helpdesk Report. Institute of Development Studies. DOI: 10.19088/K4D.2021.098

\section{About this report}

This report is based on six days of desk-based research. The K4D research helpdesk provides rapid syntheses of a selection of recent relevant literature and international expert thinking in response to specific questions relating to international development. For any enquiries, contact helpdesk@k4d.info.

K4D services are provided by a consortium of leading organisations working in international development, led by the Institute of Development Studies (IDS), with the Education Development Trust, Itad, University of Leeds Nuffield Centre for International Health and Development, Liverpool School of Tropical Medicine (LSTM), University of Birmingham International Development Department (IDD) and the University of Manchester Humanitarian and Conflict Response Institute (HCRI).

This report was prepared for the UK Government's Foreign, Commonwealth \& Development Office (FCDO) and its partners in support of pro-poor programmes. Except where otherwise stated, it is licensed for non-commercial purposes under the terms of the Open Government Licence v3.0. K4D cannot be held responsible for errors or any consequences arising from the use of information contained in this report. Any views and opinions expressed do not necessarily reflect those of FCDO, K4D or any other contributing organisation.

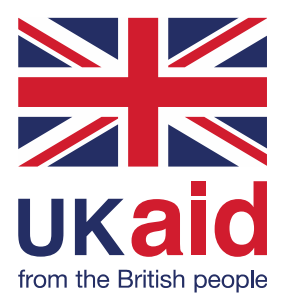

(c) Crown copyright 2021. 